\title{
The Status and Influence Factors of Science and Technology Talents Sharing in SMEs
}

\author{
Liu Qunhui \\ School of Law and Politics \\ Lingnan Normal University \\ NO.29, Cunjin Road, Chican District, Zhanjiang, 524048, China
}

\begin{abstract}
The aim of this study was to explore the current situation and the main influencing factors of science and technology talents sharing in Chinese SMEs. Based on previous research, an empirical study was conducted using a specially designed structured questionnaire survey on 145 SMEs in different industries in Guangdong Province. The results show that: (1) SMEs have diverse way to sharing technology talents; (2) SMEs prefer to project sharing, alliance sharing and consultative sharing more than commission sharing and borrowed sharing; (3) there are some macro and micro barriers in the process of talent sharing, such as unbalanced industrial structure, household registration system, and income distribution, etc.. The findings may help shed light on some confusing problems in SMEs' talent sharing in the process of contemporary collaborative innovation, and to increase understanding how to facilitate and enhance the collaborative innovation in Chinese business environment.
\end{abstract}

Keywords-science and technology talents, talents sharing, small and medium enterprise, collaborative innovation

\section{INTRODUCTION}

Innovation is a complicated project in practice, and many small and medium-sized enterprises (SMEs) will be faced with some difficulties and challenges in their independent innovation process. As a means of gaining important resources and of reducing the costs and risks associated with innovation, collaborative way has been employed in the realm of practice by SMEs[1]. As one of the most important resources of enterprise innovation, the innovative talented people such as science and technology talents is both most vigorous source of enterprise innovation and key element of collaborative integration[2]. Science and technology talent, as its name implies, is that who has excellent scientific and technological quality, strong ability of research and development, technological innovation and administrative capacity of science and technology organization (Talent dictionary, 1987).

Without a doubt, the sharing of science and technology talents can solve the problem of shortage of innovative talents in SMEs. However, with the deepening of collaborative innovation, the problem of talent sharing gradually emerged. In the process of collaboration practice, SMEs could not share and integrate the science and technology personnel effectively; science and technology talent resources can't be fully utilized, and can't create the expected synergies[3]. In a sense, talent sharing is a challenging issue throughout SMEs in China.

In the realm of inquiry, scholars have researched several aspects of these talents sharing, including their reasons, organizational modes, risk and key influencing factors, and the benefits distribution of talents sharing. Concerns about the mode of talent sharing, scholars divided it into various types from different perspectives. From the perspective of the usage rights of technological talents, Zhang X M analyzed the sharing mode of talent leasing, commission, borrowing and migratory birds[4]. Li X conceptualized two forms of "manufacturers to suppliers" and "suppliers to manufacturers"[5]. According to the relationship among the organizations, Gao $\mathrm{Z} G$ divided the sharing mode of science and technology talents into three types: project cooperation, non-equity strategic alliance and equity strategic alliance[6]. Fei Y Y et al. (2012) explored the talent sharing model suitable for technological innovation alliance.

On the factors that lead to the risk of talent sharing, scholars have conducted a number of in-depth researches on the specific mode of talent sharing from multiple angles, and constructed a system of evaluation and measurement. Susan (2006) analyzed the relationship between the governance structure and the degree of risk of talent sharing in research and development alliance from the perspective of transaction cost. Xiao L N et al. (2011) analyzed the risk factors of talent sharing in the alliance of industries, universities and research institutes and constructed the model of risk evaluation. Through reasonable assumptions and with the research methods of game theory, Gao Z G (2011) made a quantitative deduction and analysis of the decision-making on the horizontal integration and sharing of businesses of enterprises with utility heritage.

In addition, scholars have also done some research on the obstacles and mechanism of talent sharing. On the basis of the research of the talent sharing and the talent sharing effect, Niu $\mathrm{C} \mathrm{H}$ et al. analyzed the features of talent sharing effect and the mechanism of talent sharing on SMEs' technology innovation in terms of information communication, technology choice, interactive synergy, knowledge learning and technology exploration[7]. Zheng Q, Wang H, Deng Y, et al. studied four types NGOs including commercial chamber, professional association, think tank and alumni association, mainly analyzing the functions, mechanism and mode of these NGOs in promoting talent exchange between Sino-Canada[8]. In the sharing mechanism of science and technology talents, the scholars divided it into two types: micro and macro control mechanism [9]. They proposed that the micro mechanism is mainly driven by economic and non-economic interests to adjust the choices of both technical personnel individuals and employers, and the macro-control mechanism refers to the government policies about management, regulation and control on science and technology talent sharing[10]. On the basis of full study of the existing literature and the perspective of 
information asymmetry, Gao Z (2012) showed the risk causes and avoidance measures in the process of sharing science and technology talent among enterprises by adverse selection and the moral hazard brought by the economic organizations, and gave some methods to reduce sharing risk.

Although this literature has contributed a lot of knowledge about the antecedents, modes, influencing factors and other issues of talents sharing, it is largely based on the economic models deduction or theoretical analysis. There is relatively little investigation or empirical research known about on the current situation and hinder factors in Chinese SMEs' talents sharing. In order to better understand the real situation and difficulties in science and technology talents sharing and to better promote the talents sharing activities in SMEs, it is necessary to investigate the status and problems in the process of talents sharing so as to explore the main obstacle factors and find effective measures for SMEs' talents sharing practice.

Therefore, this paper conducts a sampling survey using a specially designed structured questionnaire focus on the SMEs' status of science and technology talent possession and needs of talent sharing; adoption of collaborative mode and talents sharing practices; and the main factors affecting the sharing of technical talents in different industries in Guangdong Province. Then, this research analyzes statistically the questions mentioned above and presents a theoretical framework to promote talents sharing mechanism accordingly. The results may shed light on some confusing problems in talent sharing in the process of contemporary collaborative innovation and may be helpful to increase understanding how to facilitate and enhance the science and technology talents sharing in SMEs in Chinese business environment.

\section{SAMPLE AND PROCEDURES}

The sample frame for this horizontal study is SMEs that have recently participated in or want to participate in the collaborative system. The firms were selected from lists provided by local Chambers of Commerce and mainly distributed in electronics and communications equipment manufacturing, information technology, biopharmaceutical, textile and other industries in Guangdong Province.

A questionnaire was designed and mailed to 200 technical managers or executive officer along with an informational letter stating the research purpose. The respondents should understand not only the business innovation strategy and industry trends, but also the process of cooperate innovation. They were asked to answer for their business enterprises. A total of 145 questionnaires were returned, leading to an effective response rate of $72.5 \%$. As an informant validity check, all respondents provided information about their position, the number of years they had worked for the focal firm and their degree of familiarity with the innovation activity in questionnaire. This information revealed that respondents were highly knowledgeable about the talents sharing in collaborative innovation and had substantial experience with their firm. Accordingly, our sampling approach appears to have been quite successful in identifying knowledgeable and experienced key informants.
The rate of firms ranged from 5 to 10 years was $43.4 \%$, 3 to 5 years was $27.2 \%$. Only $10.5 \%$ was over 10 years, and the rest was under 3 years. With a standard number of employees of 2,000, 58.9\% were small firms, and $41.1 \%$ were medium enterprise. According to the high-tech and traditional industry classification, the former rate was $50.25 \%$, and the latter rate was $49.75 \%$.

\section{DESCRIPTIVE ANALYSIS}

This section presents the main descriptive results emerging from the analysis in these areas: (1)the science and technology talents status and sharing needs;(2) sharing mode of science and technology talents; (3)factors affecting science and technology talents sharing.

\section{A. Science and Technology Talents Possession Status and Sharing Needs of SMEs}

With increasing competition between companies, the attraction and retention as well as the integration of science and technology talent in China has been considered to be one of the most challenging tasks in human resource management practice due to the severe shortage of high-end technical talent in Chinese labor market[11]. In order to understand the SMEs' status of science and technology talent possession and needs of talent sharing, this study designed five questions to provide information about those issues (Table 1). Informants were asked to indicate the degree to which they agree with each statement of a series of talent possession status and sharing needs, based on a five-point Likert scale anchored with "strongly disagree" and "strongly agree".

TABLE I. STATUS AND NEEDS OF SCIENCE AND TECHNOLOGY TALENTS

\begin{tabular}{c|l|l|l|l|l}
\hline \% of firms & $\begin{array}{c}\text { Strongly } \\
\text { disagree }\end{array}$ & $\begin{array}{c}\text { Somewhat } \\
\text { disagree }\end{array}$ & Generally & $\begin{array}{c}\text { Somewhat } \\
\text { Agree }\end{array}$ & $\begin{array}{c}\text { Strongly } \\
\text { Agree }\end{array}$ \\
\hline $\begin{array}{c}\text { Our company can } \\
\text { attract R\&D talents }\end{array}$ & $13.79 \%$ & $41.38 \%$ & $34.48 \%$ & $14.48 \%$ & $9.66 \%$ \\
\hline $\begin{array}{c}\text { Our talents can meets } \\
\text { innovation needs }\end{array}$ & $35.17 \%$ & $26.90 \%$ & $22.07 \%$ & $12.41 \%$ & $10.34 \%$ \\
\hline $\begin{array}{c}\text { Don't need to share } \\
\text { talents with others }\end{array}$ & $33.79 \%$ & $31.72 \%$ & $19.31 \%$ & $10.34 \%$ & $4.83 \%$ \\
\hline $\begin{array}{c}\text { Often share talents } \\
\text { with others }\end{array}$ & $15.56 \%$ & $20 \%$ & $33.33 \%$ & $17.78 \%$ & $13.33 \%$ \\
\hline $\begin{array}{c}\text { Talents sharing is } \\
\text { difficult }\end{array}$ & $11.03 \%$ & $16.55 \%$ & $20.69 \%$ & $26.9 \%$ & $24.83 \%$ \\
\hline
\end{tabular}

The statistical results show that most of sample SMEs could neither attract enough excellent technical talent nor meet the needs of innovative activities. The results indicate that the majority of respondents believe that it is necessary for their enterprises to share technical personnel with other organizations. Meanwhile, the results show that the science and technology talent sharing activity is quite widespread in SMEs, and more than half of those companies often share technical talent with other organizations. Nevertheless, many companies believe that talent sharing is very difficult in current environment.

\section{B. The Science and Technology Talents Sharing Mode}

According to the statistical results showed in Table 1, we assume that science and technology talents sharing is a desirable collaborative activity expected by SMEs. Table 2 shows results concerning the organizations with which these 
sample firms usually shared talents: $82.76 \%$ shared with the scientific research institutes; $62.07 \%$ of the sample shared talents with their suppliers; $41.38 \%$ shared with their customers; $18.62 \%$ shared with peer enterprise; and $13.79 \%$ shared with other organizations. The results indicate that SMEs are more inclined to share talents with scientific research institutes and supplier companies but less to share with their peers companies.

TABLE II. SHARE WITH WHAT SUBJECT/ORGANIZATION

\begin{tabular}{ll}
\hline \multicolumn{1}{c}{ Organization/subject shared with } & \% of firms \\
\hline Scientific research institutes & $82.76 \%$ \\
\hline Supplier & $62.07 \%$ \\
\hline Customer & $41.38 \%$ \\
\hline Peer enterprise & $18.62 \%$ \\
\hline Other organization & $13.79 \%$ \\
\hline
\end{tabular}

What kinds of modes are generally used for talents sharing? Practically, it depends on the given situation and the special enterprise. However, there are some widely used experiences and modes for different firm. This study listed five widespread used forms of talent sharing for informants to select according the actual situation of their companies adopted and want to adopt. These five forms are commission sharing, borrowed sharing, project sharing, consultative sharing and alliance sharing(Table 3).

TABLE III. MODE OF ADOPTED AND WANT TO ADOPT

\begin{tabular}{lcc}
\hline \multicolumn{1}{c}{ Mode of sharing } & $\begin{array}{c}\text { Adopted } \\
\text { \% of firms }\end{array}$ & $\begin{array}{c}\text { Want to adopt } \\
\text { \% of firms }\end{array}$ \\
\hline Commission sharing & $21.38 \%$ & $7.59 \%$ \\
\hline Borrowed sharing & $40.69 \%$ & $13.10 \%$ \\
\hline Project sharing & $57.24 \%$ & $62.76 \%$ \\
\hline Consultative sharing & $45.52 \%$ & $52.41 \%$ \\
\hline Alliance sharing & $24.83 \%$ & $37.24 \%$ \\
\hline
\end{tabular}

Commission sharing refers to that company entrusted their specific $R \& D$ tasks to the technical personnel of scientific research institutes, universities and other enterprises. Borrowing sharing refers to the enterprise hired part-time technical personnel in other organizations and pay not only a certain fee to the organization which the talents belongs to, but also rewards to the technical personnel. Project sharing refers to the enterprise established short-term cooperation with other organization because of technical development or project research needs. Consultative sharing refers to the appointment of external well-known experts as technical consultants and other positions to provide technical services for enterprises. Finally, alliance sharing refers to the establishment of longterm and stable cooperation between enterprises and other organizations in the process of industrial technology innovation.

The results in Table 3 indicate that most firms had multiple modes to share talents and a large percentage were realized the talents sharing through borrowed sharing, project sharing and consultative sharing. An additional result concerns the preferences of the firm in talents sharing: project sharing, alliance sharing and consultative sharing seem to be favored by firms more than commission sharing and borrowed sharing.

\section{Factors Affecting Talents Sharing}

SMEs need to integrate and share science \& technology talents to promote technology progress and innovation. However, it is difficult to achieve the desired effect in the process of operation in fact. Therefore, another important purpose of this study is to discern the key underlying reasons for the difficulty of technical talents sharing. Thus, the participants were required to identify the main factors which affected the talents sharing in the process of collaborative innovation.

In the light of the existing literature, the main factors affecting the sharing of scientific and technological talent can be divided into macro and micro levels. At the macro environment and policy level, regional industrial structure, social insurance, social welfare, household registration system, local protectionism, regional human resources capacity, talent sharing service platform and mechanism, legal system and other factors will affect the effective sharing of technical personnel. From the micro level, the benefits, costs, risks and incentive mechanism will affect the effective sharing of talents. So, this study set out four sets of influencing factors for the participants to choose: (1) macroeconomic and policy factors;(2) company's benefits, costs and risk factors; (3) the attribution of innovative achievements of talent sharing; and (4) Motivation for the shared technical personnel.

TABLE IV. FACTORS OF AFFECTING THE SHARING OF TECHNICAL TALENTS

\begin{tabular}{|c|c|c|}
\hline Factors & Items & \% of firms \\
\hline \multirow{6}{*}{$\begin{array}{l}\text { Macro- } \\
\text { economic } \\
\text { and } \\
\text { policy }\end{array}$} & Unbalanced local industrial structure & $57.24 \%$ \\
\hline & $\begin{array}{l}\text { Social insurance, welfare, household registration } \\
\text { system and other barriers }\end{array}$ & $51.03 \%$ \\
\hline & Regional protectionism & $17.24 \%$ \\
\hline & Regional support capacity of human resources & $22.07 \%$ \\
\hline & Absence of service platform and mechanism & $55.56 \%$ \\
\hline & Deficiency of legal system of sharing & $53.33 \%$ \\
\hline \multirow{4}{*}{$\begin{array}{l}\text { Firm’s } \\
\text { benefits, } \\
\text { costs and } \\
\text { risk }\end{array}$} & Can't necessarily increase the total income & $32.41 \%$ \\
\hline & Can't necessarily reduce the cost of talent & $28.28 \%$ \\
\hline & Difficult to determine the degree of sharing & $64.14 \%$ \\
\hline & Will lead to the loss of intangible assets & $81.38 \%$ \\
\hline \multirow{4}{*}{$\begin{array}{l}\text { use of } \\
\text { technique } \\
\text { and } \\
\text { income } \\
\text { distribu- } \\
\text { tion }\end{array}$} & $\begin{array}{l}\text { Not free to use the achievements in scientific } \\
\text { research }\end{array}$ & $15.56 \%$ \\
\hline & $\begin{array}{l}\text { Too short use period of scientific research } \\
\text { achievements }\end{array}$ & $26.67 \%$ \\
\hline & Too high use- cost of research achievements & $57.93 \%$ \\
\hline & $\begin{array}{l}\text { Unfair distribution of economic or non-economic } \\
\text { rights and interests }\end{array}$ & $71.11 \%$ \\
\hline \multirow{4}{*}{$\begin{array}{l}\text { Motiva- } \\
\text { tion for } \\
\text { technical } \\
\text { personnel }\end{array}$} & Sharing leads to an increase workload & $23.45 \%$ \\
\hline & Sharing hinder personal career development & $56.55 \%$ \\
\hline & Human capital investment can't be rewarded & $20.69 \%$ \\
\hline & Environment is not suitable for individuals & $57.78 \%$ \\
\hline
\end{tabular}

Table 4 shows results for the statistical analysis concerning some obstacle factors in technical talent sharing: (1) on the macro level, the unbalanced regional industrial structure, social insurance / social welfare / household registration system, talent sharing service platform and mechanism, and legal system are the most important obstacle factors; (2) In terms of organizational income and risk, it is difficult to determine the degree of sharing, as well as the risk of intangible assets loss is the main obstruction; (3) As to the distribution of the sharing achievements, the high cost and the imbalanced distribution of benefits are the main obstacles; (4) As to the individual incentive mechanism, the two major obstacles are "sharing may not be conducive to personal career development" and "sharing environment is not suitable for individuals”. 


\section{DisCUSSION AND CONCLUSION}

Based on the literatures of collaborative innovation and human resources sharing, this paper conducts a sampling survey using a specially designed structured questionnaire on 145 SMEs in Guangdong Province. Then, analyze statistically the present status, sharing mode and influence factors of science and technology talent sharing.

Descriptive results associated with the status of technical talents in SMEs highlight the urgent demand of technical talents. Maybe due to the small scale, high risk and other reasons, SMEs are in the obvious disadvantage in attracting and retaining technical personnel and facing a serious shortage of innovative talents. Therefore, the sharing of science and technology talents is an effective way to solve the current insufficient of innovative talents in SMEs.

Furthermore, the evidence stresses that the way towards science and technology talents sharing does not have a unique imprinting, but it is likely to be diverse forms of commission sharing, borrowed sharing, project sharing, consultative sharing and alliance sharing. It is clear that SMEs prefer to project sharing, alliance sharing and consultative sharing more than commission sharing and borrowed sharing.

Finally, the obstacle factors analysis highlights the following critical strategies and suggestions for promoting technical talent sharing. On the one hand, the government should try to eliminate the negative effects of the macro level factors such as unbalanced regional industrial structure, social insurance /social welfare /household registration system, and build a good talent sharing service platform and legal system. On the other hand, from the micro level, the alliance of technical talents sharing should strive to build a fair and reasonable benefit distribution mechanism, risk mechanism and talent incentive mechanism.

Collectively, some useful conclusions are drawn from the statistical analysis. The findings have implications for the current collaborative innovation literature. The results also helps shed light on some confusing problems in talent sharing in the process of contemporary collaborative innovation and may be helpful to increase understanding how to enhance the efficiency of science and technology talents sharing and to promote the innovation performance of SMEs.

Perhaps the major limitation of our study is the restricted size and breadth of our sample. Although our sample included a broad swath of industries, it obtained only 145 usable responses and focuses solely on SMEs in Guangdong Province. Thus, future research efforts that make larger-scale investigation across the China country and use alternative sampling frames to do more specific analysis of the obstacles of science and technology talent sharing in-depth would nicely complement our work.

Another limitation pertains to the simple descriptive statistical analysis method of our study. SMEs' talent sharing is a complex phenomenon and affected by many factors on the broader environment. So need to establish a regression equation to explore the impact of some independent variables on it. Thus, further research efforts could provide a valuable contribution by establish the relationship between some independent variables and talent sharing, and study in depth how to design and optimize the sharing mode of science and technology talents sharing and mechanism of promotion.

\section{REFERENCES}

[1] Millson M R, Raj S P, Wilemon D. 1996.Strategic Partnering for Developing New Products.J. Research-Technology Management, 1996, 39(3), 41-49.

[2] Pucci E L, Mulder I. 2015. Star to Shine: Unlocking Hidden Talents Through Sharing and Making[C]// Distributed, Ambient, and Pervasive Interactions, 2015,85-96.

[3] Li X. 2010. Formation and Development of Human Resource Sharing Among Enterprises. J. Modern Finance\&Economics (Dec. 2010), 57-61.

[4] Zhang X M.2002. Talent sharing:a new concept.J. Human Resource, 2002(4):56-58 (In Chinese).

[5] Li XM. Formation and Development of Human Resource Sharing Among Enterprises[J]. Modern Finance \& Economics, 2010,12(30):5761 (In Chinese).

[6] Gao Z. 2012. Research on Risk of Sharing Sci-Tech Talent Among Enterprises under Information Asymmetry. J.Science of Science \& Management of S\&T (Jun. 2012), 165-171 (In Chinese).

[7] Niu C H, Yan Z Y, Zhang Y H. 2011.Mechanical Effect of the Mediumsized and Small-sized Enterprise Talent Sharing on the Technology Innovation. J. Journal of Shanxi Agricultural University, 2011.

[8] Zheng Q, Wang H, Deng Y, et al. 2013. A Study on NGO's Role on Sino-Canada Talent Exchange and Sharing. J. First Resource, 2013 (In Chinese).

[9] Tong L J, Meng W D. 2013. Bottleneck Factors and Countermeasures of Talent sharing Mechanisms in Bohai Rim Region. J. Science and Technology Management Research, 2013, 21:91-95.

[10] Guo Q. 2007.Talent-sharing Mechanism in the Yangtze River Delta:Problems and Solutions. J. Journal of Social Sciences (May, 2007), 21-27.

[11] Scullion H and Collings DG. 2011. Global Talent Management. Routledge: New York. 